\title{
A Amazônia na Rio+20: as discussões sobre florestas na esfera internacional e seu papel na Rio+20
}

\author{
The Amazon at Rio+20: the discussions on forests in the international arena and their role \\ at Rio+20
}

Joana Bezerra ${ }^{1}$

\section{Resumo}

As florestas apresentam uma situação única e muitas vezes contraditória na esfera internacional. Tema transversal, inerente às principais discussões ambientais e sociais atuais, o regime de florestas não apresenta um documento internacional de leis vinculativas. A situação do tema na Rio+20 também foi contraditória, já que apesar de perpassar os temas discutidos, as florestas não fizeram parte da agenda oficial do evento. No entanto, o momento de mudanças vivido no Brasil contribuiu para que o tema, em particular a Amazônia, fosse exaustivamente discutido em eventos paralelos. Quatro questões dominaram o debate - a construção de Belo Monte, o desmatamento, as unidades de conservação e o código florestal - evidenciando o papel central da Amazônia não apenas no Brasil, mas também na esfera internacional. O objetivo deste artigo é apresentar uma análise dessa qualidade singular do tema florestas na agenda ambiental internacional e o papel da Amazônia no encontro das Nações Unidas.

Palavras-chave: Amazônia. Florestas. Políticas públicas. Política ambiental internacional.

\begin{abstract}
Forests have a unique and often contradictory situation in the international sphere. A crosscutting theme, inherent to the main current environmental and social discussions, there is no clearly cut and defined law for forestry. The situation of the theme at Rio+20 was also contradictory, since despite the fact that forestry issues were included in the matters under discussion, they were not part of the official agenda. However, the timing of changes experienced in Brazil contributed to the fact that the theme, in particular the Amazon rainforest, was thoroughly discussed at parallel events. Four issues dominated the debate: the construction of the Belo Monte dam, deforestation, conservation units and the forestry code, highlighting the central role of the Amazon not only in Brazil, but also in the international community. The aim of this article is to present an analysis of this unique quality of forests in the international environmental agenda and the role of the Amazon at the United Nations meeting.
\end{abstract}

Keywords: Amazon. Forests. Public policies. International environmental policies.

1 Doutora em Ambiente e Sociedade pela Universidade Estadual de Campinas. Consultora da FGV/Projetos. Endereço: Praia de Botafogo 228 - Lado B, $6^{\circ}$ andar, CEP 22250-906, Rio de Janeiro - RJ, Brasil. Email: jcbezerra@hotmail.com 


\section{Introdução}

Desde os tempos do Brasil colonial, a Amazônia é considerada um elemento importante na pauta da política externa do país. No século XX, a região tornou-se definitivamente alvo de interesse universal, por sua relevância central para o futuro do planeta e para a construção de um horizonte de desenvolvimento global sustentável. Não há desenho do futuro no qual a Amazônia não ocupe um lugar de destaque. Por esse motivo, a região se destacou na agenda oficial da Conferência das Nações Unidas sobre o Desenvolvimento Sustentável, a Rio+20. Isso se deu mais por sua ausência do que por sua rarefeita presença; cabendo lembrar que o debate em torno dela se deu prioritária e intensamente em eventos paralelos promovidos pela sociedade civil, pela academia e, mesmo, pelo governo brasileiro.

O objetivo deste artigo é analisar o papel da Amazônia nas discussões da Rio+20. No entanto, para entender o que aconteceu no Rio de Janeiro em junho de 2012, é preciso voltar um pouco no tempo e analisar o lugar ocupado pelo tema das florestas na Rio 92 e nesses vinte anos entre as duas conferências. $\mathrm{O}$ artigo é dividido em quatro seções. A primeira é dedicada à Amazônia e procura explicar o porquê da importância da floresta tropical sul-americana. A segunda seção foca as discussões sobre florestas na esfera internacional. A terceira seção apresenta uma análise sobre a Amazônia na Rio+20, discutindo também o papel do governo brasileiro. $\mathrm{Na}$ quarta seção são apresentadas as considerações finais.

\section{Amazônia}

A condição natural do homem é a de escassez (OPHLUS, 1977). No entanto, o aparente fluxo ilimitado de recursos dos últimos séculos ofuscou essa condição. Hoje, a realidade traz esse fato para o centro do debate internacional. Vivemos uma crise cuja existência não pode mais ser negada. Seres humanos e a natureza sempre estiveram interligados, e a história humana é, de fato, a história de sua relação com a natureza (GUIMARÃES, 1991). No entanto, o aumento do impacto da ação humana na natureza alterou o significado do meio ambiente, que deixou de ser um fator estável e entrou para a agenda política nacional e internacional (HURRELL e KINGSBURY, 1992). Estamos vivenciando uma reavaliação da natureza no cenário global. Nesse contexto, a Amazônia, um dos três grandes estoques de natureza do mundo ${ }^{2}$ (BECKER 2007), ganha um novo espaço nacional e internacionalmente.

A Amazônia é um lugar único. A floresta se estende por oitos países e a Guiana Francesa, representando 1/20 da superfície do planeta Terra (VIANA, 2001). A floresta tropical sul-americana é o lugar onde vivem de 1,8 milhão de espécies de plantas, animais e micro-organismos (BECKER e STENNER, 2008), englobando um terço da área tropical de florestas (FALEIRO, 2001). Além disso, é o lugar mais biodiverso do mundo (EWERS e LAURANCE, 2006; DA SILVA, RYLANDS e DA FONSECA, 2005; GARDA, DA SILVA e BAIÃO, 2010; HOORN et al 2010), onde se pode encontrar a bacia hidrográfica mais importante do planeta, com 17\% de toda a água doce existente (BECKER, 2004). Vale ressaltar que ainda há muito o que descobrir na Amazônia (LEWINSOHN, 2006), o que significa que sua riqueza natural vai muito além do que conhecemos atualmente.

A Amazônia é única, mas não é homogênea. Sua diversidade fica evidente quando se tornam claras as diferentes fronteiras no interior da própria floresta brasileira. Ela tampouco se restringe a elementos naturais. A definição política da floresta brasileira vai além dos limites biofísicos do bioma. Nela existem diferentes realidades físicas, biológicas e antropológicas; diferentes características que transformam a floresta em várias florestas. Há, portanto, várias Amazônias dentro das fronteiras amazônicas.

${ }^{2}$ Os outros dois são: Antártida e os fundos marinhos. 
Hoje, a Amazônia alcança relevância nunca antes vista por duas razões principais. A primeira é o aumento da importância do regime do clima no contexto global, trazendo à tona temas como a governança da biodiversidade. A segunda é a mudança na maneira como a natureza é representada, movimento que é atribuído à crescente importância da mesma nas esferas política e econômica. Todas as discussões presentes e futuras sobre o meio ambiente passam pela floresta sul-americana, grande reguladora de serviços ecossistêmicos. Apesar de ter ocupado um lugar no cenário internacional desde os tempos coloniais, sem dúvida, neste novo contexto, a Amazônia passa a ter uma importância estratégica fundamental.

\section{Florestas na Esfera Internacional}

Florestas atravessam as principais discussões internacionais atuais. Falar de florestas é falar sobre mudanças climáticas. Nelas se encontram grandes estoques de carbono na vegetação e no solo. Falar de florestas é falar de biodiversidade, de recursos genéticos ainda pouco conhecidos. Estima-se que 70\% das espécies de plantas e animais terrestres sejam encontrados em ecossistemas de florestas (HOLMGREN, 2010). Falar de florestas também é falar de desertificação. As florestas proveem benefícios ecológicos-chave que reduzem a vulnerabilidade de ecossistemas secos. Um dos objetivos da Convenção das Nações de Combate à Desertificação é proteger florestas. Falar de florestas também é falar de populações indígenas, que são dependentes das florestas para suas vidas, e do conhecimento tradicional que essas populações detêm. Falar de florestas é falar sobre os serviços ecossistêmicos, que passam pela água, pelo oxigênio, pelo nitrogênio e pelo carbono. Na Amazônia, já há muitas cidades de médio ou grande porte numa situação especial: apresentam problemas urbanos em meio à imensa floresta. Isso, ao menos, para o Brasil, envolve questões estratégicas muito complexas - como política de ocupação, uso de tecnologias, exploração de riquezas, turismo etc. - influindo, via centros urbanos, na floresta ao redor. Portanto, é difícil entender como um tema tão central para as discussões de hoje pode ficar relegado a um segundo plano.

A criação, em 1945, da Organização das Nações Unidas para Alimentos e Agricultura (em inglês FAO) e do seu departamento de florestas marca a entrada do tema "florestas" na arena internacional de discussão (HOLMGREN, 2010). Em outras palavras, é a partir desse momento que florestas começam a ganhar um espaço na estrutura internacional de discussão. No entanto, foi apenas em 1980, com a repercussão internacional do desmatamento de florestas tropicais, que o tema efetivamente se tornou uma questão política. Também foi na década de 1980 que a Amazônia passou a ocupar um lugar de destaque na arena política internacional. Imagens da floresta brasileira devastada correram o mundo, levantando questões relacionadas à capacidade do país de conservar a floresta. Somou-se a isso o fato de os direitos indígenas terem se tornado um tema de relevância crescente naquele momento. No âmbito nacional, a década de 1980 também foi emblemática por causa da repercussão internacional em torno dos conflitos entre seringueiros, de um lado, e madeireiros e pecuaristas, de outro, que culminaram no assassinato de Chico Mendes, líder seringueiro ambientalista conhecido mundialmente por sua luta contra as forças destrutivas na Amazônia. Naquele momento, o Brasil foi visto como o grande vilão do meio ambiente. Pode-se dizer que entre os motivos para o Brasil se oferecer como sede para a Conferência das Nações Unidas sobre Meio Ambiente e Desenvolvimento em 1992, certamente, estava a tentativa de desfazer ou amenizar essa imagem negativa.

A ausência de debate em torno das florestas na Agenda da Rio+20 contrasta com o que ocorreu vinte anos antes, na Rio 92. Na Conferência das Nações Unidas sobre Meio Ambiente e Desenvolvimento, as florestas eram parte da agenda oficial. No entanto, apesar de se encontrar entre os principais eixos de discussão, o tema das florestas se mostrou especialmente complexo. Os negociadores não conseguiram chegar a um consenso e, ao contrário dos outros principais temas do encontro de 1992 - mudança climática, desertificação e biodiversidade -, o tema não deu origem a uma convenção. Foi abandonado ainda nas negociações preparatórias, devido ao grande desentendimento entre governos sobre a necessidade real de um tratado sobre florestas. Ao invés disso, a Rio 92 deu origem aos Princípios da Floresta, que englobava todos os tipos de floresta, embora não fosse um documento com força legal. Ao lado desse documento, as florestas também se tornaram um dos capítulos da Agenda 21, um dos documentos finais da Conferência sobre Meio Ambiente e Desenvolvimento, que tem como objetivo servir de instrumento para o planejamento sustentável de uma localidade (MINISTÉRIO DO MEIO AMBIENTE, 2012). 
Já nas discussões preparatórias, ficou clara a existência de uma divisão norte-sul sobre o tema. Enquanto os países do norte, como EUA e Canadá, além da União Europeia, reforçavam o princípio da responsabilidade global sobre a preservação de florestas -, entendendo florestas tropicais como patrimônio do mundo -, os países do sul frisavam os direitos soberanos dos estados de utilizarem seus recursos naturais (DIMITROV, 2005) e exigiam compensação financeira pela proteção de suas florestas (HOLMGREN, 2010). Apesar de não se ter alcançado uma convenção para florestas, a importância delas ficou clara na Rio 92, já que o tema foi central na fase preparatória. Além disso, o impasse atingido nas reuniões que antecederam a Rio+20 evidenciaram a complexidade do tema e a necessidade de continuação do debate.

Entre 1992 e 2012, o tema não passou em branco no âmbito internacional. Muito pelo contrário, a década de 1990 ficou conhecida como a década das grandes conferências. No entanto, em termos de resultados práticos, pouco foi alcançado. Reuniões foram marcadas, instituições criadas e, mesmo assim, o tema permanece até hoje sem um documento de leis vinculativas, ${ }^{3}$ ou seja, que tenha força suficiente para ser implementado. Sem um documento com força de lei, pode-se dizer que, atualmente, um regime de florestas baseado em leis - no sentido mais tradicional do termo - internacionais não existe (DIMITROV, 2005). Depois do fraco resultado da Rio 92, alguns países signatários do Acordo Internacional sobre Madeira Tropical de 1983 tentaram expandir o texto do documento para que o mesmo incluísse as florestas boreal e temperada. No entanto, os EUA e União Europeia foram contra mudanças no escopo do Acordo. Portanto, o foco do documento permaneceu exclusivamente em florestas tropicais, presente apenas em países em desenvolvimento.

O regime de florestas - ou a falta de um - mostra como mesmo uma presença forte na agenda internacional é incapaz de forçar mudanças quando grandes interesses são confrontados. Apesar de ser um tema que perpassa várias discussões em voga hoje - como as mudanças climáticas, a governança da biodiversidade, a desertificação, a redução de emissões de desmatamento e degradação e os serviços ecossistêmicos, entre outros -, o regime de florestas não conseguiu se impor efetivamente. Os esforços internacionais em sua direção não impediram que governos politicamente fracos se opusessem a um regime de políticas para a gestão sustentável de florestas (DIMITROV, 2005). Por outro lado, governos de peso têm se esforçado para parecer ocupados em discussões internacionais, ao mesmo tempo em que têm feito de tudo nas discussões para que nenhum acordo seja atingido. O quadro internacional tampouco tem facilitado a coordenação de políticas para combater o desmatamento. Estados tomam decisões unilaterais sem respaldo em nenhum aparato internacional.

Assim, a trajetória das negociações internacionais sobre florestas é singular, já que encontros, reuniões e até mesmo instituições foram criadas sem que um acordo fosse assinado. Na década de 1990, em um encontro da Comissão das Nações Unidas sobre Desenvolvimento Sustentável, um dos resultados da Rio 92, os estados membro da Organização das Nações Unidas (ONU) reconheceram a necessidade de se criar uma esfera internacional de discussão dedicada às florestas. Com isso, foi criado o Painel Intergovernamental sobre Florestas (em inglês IPF), que teve quatro encontros entre 1995 e 1997. O impasse sobre a necessidade de uma convenção sobre florestas e sobre a assistência financeira a países em desenvolvimento para protegerem suas florestas levaram o grupo de estados que faziam parte do IPF a criar o Fórum Intergovernamental sobre Florestas (IFF) para continuar o debate sobre política de florestas. A posição dos países protagonistas não mudou e a questão mais controversa dos dois órgãos foi a necessidade ou não de um acordo internacional político sobre o tema (DIMITROV, 2005). No entanto, outros temas como a transferência de tecnologia, questões relacionadas ao comércio de produtos florestais e a assistência financeira também esbarraram em um impasse (ROSENDAL, 2001).

Na última sessão do IFF, em fevereiro de 2000, depois de horas de negociações sem uma decisão final, a proposta de uma convenção de floretas foi rejeitada (DIMITROV, 2005). No entanto, a falta de consenso não impediu a criação de uma instituição dentro das Nações Unidas, o Fórum de Florestas das Nações Unidas

\footnotetext{
${ }^{3}$ Em inglês "hard Law".
} 
(em inglês UNFF), que responde diretamente ao Conselho Econômico e Social das Nações Unidas. Foi nesse ambiente que o caráter único das discussões sobre florestas ficou mais evidente: apesar de discordarem entre si em questões políticas, quando o assunto era o mandato do UNFF, os estados trabalhavam em sintonia para a criação da instituição. A explicação para esse quadro contraditório é o fato de o tema 'florestas' fazer parte obrigatória das questões ambientais internacionais - nenhum estado hoje pode se dar ao luxo de não participar das discussões a respeito. Evitar sistematicamente o debate sobre florestas causaria um estrago político muito alto para todos os países. Por isso, há consenso sobre a criação de uma instituição que, na prática, é vazia institucional e politicamente; entendimento esse que acaba quando a discussão volta a focar temas como a elaboração de uma convenção sobre florestas. Nesse momento, os estados retomam sua postura irredutível e o impasse impossibilita qualquer avanço.

Esse é um exemplo muito claro do conservadorismo dinâmico, ou seja, da estratégia voltada para mudar o suficiente para que tudo possa continuar o mesmo (GUIMARAES, 1991). A criação da UNFF pretendeu mostrar ao mundo que os países haviam começado a abordar efetivamente a questão das florestas. Entretanto, a instituição não tem poderes efetivamente, e os países continuam com suas posições imutáveis. A UNFF passa a impressão de que algo está sendo feito, quando na prática nenhuma decisão política é tomada. O Fórum não passa de um teatro montado para o público, e o espetáculo é o desperdício de recursos - financeiros e humanos - para manter um aparato internacional de diálogo de "faz de conta".

Quando o tema envolve instituições e tratados sobre florestas, não se pode esquecer o Tratado de Cooperação Amazônica. O Tratado foi assinado na década de 1970, em plena ditadura militar, no Brasil sob o comando do general Ernesto Geisel (1974-1979). Com o Tratado, a Amazônia passou a fazer parte da linha de frente da política externa brasileira. Um dos fatores que contribuiu para a assinatura do Tratado Amazônico foi justamente a assinatura de outro documento internacional na região, o Pacto Andino (ANTIQUERA, 2006). Com isso, a necessidade de um documento assinado entre os sul-americanos que incluísse o Brasil ficou evidente. Apesar de ter sido assinado em 1978, o Tratado de Cooperação Amazônica nunca chegou a ocupar um lugar de destaque na política do Brasil, em grande parte porque não se referia aos temas mais relevantes para o país naquele momento: segurança e recursos naturais. ${ }^{4}$

A grande repercussão em torno das mudanças climáticas colocou as florestas de volta no centro das discussões internacionais, principalmente, na década de 2000. Apesar da crise econômica mundial ter afetado negativamente as discussões sobre a continuação do Protocolo de Quioto - acordo internacional, firmado no âmbito da Convenção-Quadro das Nações Unidas sobre Mudanças Climáticas, visando diminuir a emissão de gases de efeito estufa e que está em vigor de 2005 até o final de 2012 - alguns aspectos das mudanças climáticas ganharam força para se desenvolverem sem a necessidade de continuação do Protocolo. É justamente nesse ponto que as florestas ficam em evidência, já que os aspectos em destaque são temas intimamente relacionados a florestas, como a redução de emissões por desmatamento e degradação e os serviços ecossistêmicos. Apesar de não fazerem parte do Protocolo de Quioto, essas questões são insistentemente discutidas na esfera internacional. No Brasil, alguns estados até já apresentam leis para regular o pagamento por serviços ambientais, como é o caso do Acre.

O cenário real das florestas é muito mais complexo do que as visões simplificadas que circulam em ambientes urbanos. As contradições presentes nos centros urbanos também são verificadas nas florestas tropicais, mas num contexto completamente diverso, o que torna essa realidade extremamente peculiar. As florestas tropicais estão entre as regiões mais pobres do mundo. Mas, mesmo sendo a casa de pessoas muito pobres, também abrigam grandes latifundiários cujo ganho com a venda de seus produtos, tanto no mercado interno quanto no externo, não se distribui pela região. Outro ponto que reflete a complexidade do tema florestas refere-se ao crescimento (em alguns casos, vertiginoso) de cidades nelas situadas. Um caso bem ilustrativo é Manaus, capital do estado do Amazonas, cidade que já enfrenta todos os problemas de uma

\footnotetext{
${ }^{4}$ Em 1995, os países signatários do TCA - Brasil, Bolívia, Colômbia, Equador, Guiana, Peru, Suriname e Venezuela - decidiram criar uma secretaria permanente para fortalecer o Tratado.
} 
grande metrópole, mas com o grande diferencial de estar no meio da Amazônia. O paradigma de populações ribeirinhas já há muito tempo não apreende por completo a realidade das populações da floresta tropical sulamericana.

$\mathrm{O}$ fato de as florestas abrangerem diversas discussões significa que o tema é indiretamente abordado em vários acordos e até mesmo em convenções internacionais. Por exemplo, as questões relacionadas ao comércio de produtos das florestas são parcialmente abordadas pela Convenção sobre o Comércio Internacional de Espécies de Flora e Fauna Selvagens em Perigo de Extinção (em inglês CITES) e pelo Acordo Internacional das Madeiras Tropicais (em inglês ITTA). Já a conservação é abordada pela Convenção da Diversidade Biológica (em inglês CBD) e pela Convenção de Ramsar sobre zonas úmidas (BROWN, 2001). No entanto, esse quadro não apresentou um saldo positivo. Sem uma convenção focada em florestas, o tema fica diluído e é facilmente ignorado. Essa abordagem fragmentada dificulta uma visão mais ampla que compreenda a complexidade do tema e as interligações de cada questão abordada pelos diferentes acordos e convenções.

A Assembleia Geral da ONU declarou 2011 o Ano Internacional das Florestas. A iniciativa tinha como objetivo sensibilizar a população mundial para a conservação e o desenvolvimento sustentável de todos os tipos de florestas. Entretanto, pouco foi feito, tanto no âmbito internacional quanto no nacional, e apenas aqueles que trabalhavam com o tema ficaram cientes.

Os vinte anos que se passaram entre a Rio 92 a Rio+20 foram intensos em termos de debate, mas fracos em termos de resultados práticos. O que se conseguiu foi mais por ações unilaterais do que por meio da cooperação. A próxima seção é dedicada a Rio+20 e ao papel da Amazônia.

\section{A Conferência das Nações Unidas sobre Desenvolvimento Sustentável e a Amazônia}

O documento preparatório da Rio+20, intitulado "Rascunho Zero", definiu os dois principais temas da Rio+20: a economia verde no contexto do desenvolvimento sustentável e o quadro institucional para esse desenvolvimento sustentável. ${ }^{5}$ De acordo com o documento, a economia verde irá contribuir para que sejam atingidos os objetivos-chave, como a erradicação da pobreza e a segurança alimentar, com base nos Princípios do Rio, ${ }^{6}$ em particular no princípio da responsabilidade comum, porém, diferenciada. Portanto, a economia verde seria uma maneira de atingir o desenvolvimento sustentável, que continua sendo o objetivo mais abrangente.

Em relação ao quadro institucional para o desenvolvimento sustentável, o documento é ainda mais vago. O fortalecimento e a reforma do quadro deveria integrar os três pilares - as esferas econômica, ambiental e social - do desenvolvimento sustentável e promover a implementação da Agenda 21. Deveria ainda prover um guia político liderado por governos para o desenvolvimento sustentável - especificando ações para que este seja atingido -, além de monitorar o progresso da implementação da Agenda 21 e reforçar a coerência entre as agências, fundos e programas da Organização das Nações Unidas.

O documento final, intitulado "O Futuro que Queremos", não foi muito além em termos de definição do que seja uma economia verde e qual o quadro institucional para o desenvolvimento sustentável. Ele deixa a cargo de cada país decidir como vai implementar as políticas da economia verde (artigo 59). Mesmo reconhecendo a importância da avaliação de fatores sociais, econômicos e ambientais e estimulando os países a integrar essa avaliação à tomada de decisões, o documento não estabelece os objetivos do desenvolvimento

${ }^{5}$ UNITED NATIONS. Draft zero. Documento preparatório das Nações Unidas para a Rio+20. Nova York, 10 Jan. 2012a, 19p.

${ }^{6}$ Os Princípios do Rio são os princípios que estão no documento final da Conferência das Nações Unidas sobre Meio Ambiente e Desenvolvimento em 1992. 
sustentável. Mais uma vez, fica cargo dos estados decidir como serão avaliados os fatores sociais, econômicos e ambientais (artigo 63).

Em relação ao quadro institucional para o desenvolvimento sustentável, o documento também deixa a desejar. O texto frisa a importância de instituições para alcançar o desenvolvimento sustentável, além de reconhecer a necessidade de uma reforma transparente no sistema multilateral. No entanto, não menciona que instituições seriam essas, nem que tipo de reforma no sistema global multilateral seria possível. A reforma do Programa das Nações Unidas para o Meio ambiente (em português PNUMA), com a qual todos concordavam, também não obteve grandes definições. O documento afirma que todos estão comprometidos com a reforma do PNUMA (artigo 88) e convida a Assembleia Geral da ONU a fundamentar essa reforma, que buscaria fortalecer sua governança, obter recursos financeiros seguros e aumentar sua voz, entre outros objetivos. A maneira como essas metas seriam atingidas não é mencionada.

O tema das florestas ficou claramente fora da Agenda da Rio+20. No "Rascunho Zero", apenas dois parágrafos foram dedicados a florestas e biodiversidade. É claro que a extensão de um texto não é um indicador de qualidade, mas o "Rascunho Zero", de fato, deixou muito a desejar. Ao invés de defender o desmatamento zero, o documento mencionava a diminuição do desmatamento e pedia a implementação do Instrumento Juridicamente Não Vinculante Sobre o Manejo Sustentável de Todos os Tipos de Florestas.

O texto final da Conferência apresenta quatro parágrafos sobre as florestas. Entretanto, a melhora de $100 \%$ no número de parágrafos em relação ao "Rascunho Zero" não foi sentida no conteúdo. A menção à diminuição do desmatamento foi retirada, e o texto enfatiza o papel vital do Fórum de Florestas da Organização das Nações Unidas.

A análise feita aqui sobre o Fórum deixa claro o que essa afirmação de fato significa. O texto pede a implementação urgente do Instrumento Juridicamente Não Vinculante Sobre o Manejo Sustentável de Todos os Tipos de Florestas. Esse instrumento foi adotado na Assembleia Geral da ONU em 2007 e seu objetivo é fortalecer o compromisso político na implementação da gestão sustentável de florestas. Apesar de ter gerado expectativas em 2007, o documento ainda não teve grande repercussão no que diz respeito a sua adoção pelos países signatários. Além disso, sua natureza não vinculativa reforça, mais uma vez, o "conservadorismo dinâmico" das discussões internacionais sobre florestas.

Apesar de não fazer parte da agenda oficial da Rio+20, foi sobre florestas que tratou um dos "Diálogos para o Desenvolvimento Sustentável", debates entre representantes de segmentos da sociedade civil para a escolha de propostas a serem enviadas para a conferência oficial. Tida como inovadora, por abrir espaço para que propostas da sociedade civil chegassem até a cúpula política, a iniciativa dos Diálogos foi do governo brasileiro. No entanto, também sofreu críticas, já que para muitos as propostas não seriam ouvidas e a participação da sociedade civil nos debates seria usada como se o documento final da Rio+20 tivesse o apoio desse setor. De fato, as três propostas escolhidas pelos participantes do Diálogo sobre florestas não fizeram parte do documento final da Conferência. As propostas foram: restaurar, até 2020, 150 milhões de hectares de terras desmatadas ou degradadas; promover ciência, tecnologia, inovação e conhecimento tradicional como forma de enfrentar o principal desafio das floresta; e desmatamento zero também até 2020.

\section{Amazônia e a Rio+20}

Ao invés de estimular uma discussão sobre florestas na Conferência, o Brasil se manteve apático, posição que talvez possa ser explicada pelo momento interno, então, vivido pelo país. Quatro temas se impuseram pela sua urgência, dominando os eventos paralelos sobre florestas. Foram eles: a construção de Belo Monte, o desmatamento, as unidades de conservação e o código florestal.

Quando estiver pronta, Belo Monte será a terceira maior hidroelétrica do mundo, atrás apenas de Três Gargantas, na China, e de Itaipu, que é divida por Brasil e Paraguai. Seu projeto é fruto da ditadura militar no 
Brasil na década de 1970, e é mais um exemplo de seu viés megalomaníaco. Foi em 1975 que o governo encomendou um estudo sobre o potencial hidroelétrico dos rios da Amazônia. O estudo ficou pronto em 1980 e um de seus resultados foi o complexo hidroelétrico de Altamira, que incluía as hidroelétricas de Babaquara e Kararaô, que a partir de 1990 seria conhecida como Belo Monte. A hidroelétrica, que vai ser construída na bacia do rio Xingu, no Pará, faz parte do Programa de Aceleração do Crescimento (PAC), que começou com o segundo mandato de Luiz Inácio Lula da Silva e ganhou segunda versão no governo de Dilma Rousseff. Em ambos os mandatos o programa é o carro-chefe dos governos, e Belo Monte, por ter gerado uma intensa polêmica, tornou-se uma das ações mais emblemáticas do PAC.

O debate sobre Belo Monte foi reaberto em 2010, quando a licença ambiental prévia para sua construção foi concedida. ${ }^{7}$ Duas questões delineiam o debate. A primeira é o seu impacto socioambiental na região. A área inundada, que inicialmente era de $1.225 \mathrm{~km}^{2}$ passou para a $516 \mathrm{~km}^{2}$ (MANSUR, 2011), atingindo 7.000 mil indígenas de 17 etnias diferentes.

A segunda questão é a sua viabilidade financeira. Devido a mudanças no projeto de engenharia e ao regime de chuvas da região, é estimado que a hidroelétrica funcione com 40\% da sua capacidade (MANSUR, 2011). Seu custo total de construção passou de R $\$ 16$ bilhões para $\mathrm{R} \$ 19$ bilhões. Em novembro de 2011, uma nova avaliação da Norte Energia S.A (NESA) estimou o valor final em R 26 bilhões (BITENCOURT, 2011).

O desmatamento na Amazônia foi outro tema que gerou debate. Foi bastante documentado que o desmatamento na região vem caindo desde 2005. É importante ressaltar que a sustentabilidade da diminuição do desmatamento ainda é incerta. O Brasil apresenta um histórico de desmatamento muito bem documentado (CHATTERJEE, 2009). Apesar da queda contínua dos últimos anos, o desmatamento na Amazônia é instável, o que torna difícil prever o que acontecerá nos próximos anos. Cabe ressaltar que desmatamento e degradação são mais fortes em países com uma estrutura institucional mais fraca (RICHARDS e JENKINS, 2007).

A diminuição da taxa de desmatamento sustenta o argumento do governo de que essa questão na Amazônia está sob controle (MAY e MILLIKAN, 2010). De fato, nos últimos anos houve um aumento no número de áreas protegidas. Foi estimado que essa mudança seja responsável por $37 \%$ da redução do desmatamento entre 2004 e 2008 (MAY e MILLIKAN, 2010). Entre 2004 e 2005, o governo brasileiro decretou o surgimento de novas áreas protegidas, cobrindo um total de $240.000 \mathrm{~km}^{2}$ (CENTRO DE GESTÃO E ESTUDOS ESTRATÉGICOS, 2011). No entanto, é importante ressaltar que, mesmo com a redução drástica do desmatamento em seu território, o Brasil ainda está no topo da lista de países com altas taxas de destruição (CGEE, 2011).

Foi no ano de 2005, quando o desmatamento na floresta atingiu limites alarmantes, que o governo deu início a mudanças que afetariam a Amazônia. Naquele ano, o Brasil vivenciou uma seca extrema que afetou severamente a floresta tropical sul-americana, a pior seca em três décadas, facilitando o espalhamento de fogo. O impacto dessa seca foi sentido em mais de 300.000 hectares de floresta, afetando mais de 400.000 pessoas (BOYD, 2008).

Em 2005 o governo brasileiro começou uma mudança institucional. As últimas décadas tornaram evidente a fraca implementação de leis florestais (BAUCH et al., 2009). Foi feita uma revisão das leis existentes e promovido um diálogo com os atores envolvidos. Até o início da década de 2000, as florestas estavam sob a responsabilidade do Instituto Brasileiro de Meio Ambiente e Recursos Renováveis (IBAMA), com exceção

7 Empreendimentos que vão causar impacto no meio ambiente precisam adquirir licenças ambientais para sua construção e operação. Há três tipos de licença: a licença prévia, a de instalação e a de operação. As três licenças, quando concedidas, valem por um tempo determinado na sua emissão e podem ser renovadas. Quando são expedidas, as licenças podem ser concedidas com condicionantes, ou seja, a licença é concedida contanto que a empresa se responsabilize por atender às condicionantes. Caso não sejam atendidas, a licença pode não ser renovada ou até mesmo revogada. 
das florestas indígenas, que estavam sob a responsabilidade da Fundação Nacional do Índio (FUNAI). O IBAMA foi criado em 1989 e estava ligado ao Ministério do Meio Ambiente. Seu objetivo era regular o setor ambiental, assim como peixes, florestas e borracha. Porém, devido à escassez de recursos e à falta de preparo de seus funcionários, o IBAMA não teve sucesso em assegurar a proteção dos recursos naturais da Amazônia.

A Lei 11.284, de março de 2006, e o decreto 6.063, de março de 2007, estabeleceram o Sistema Florestal Brasileiro (SBF), que ficou responsável pela gestão de áreas designadas para produção em áreas florestais. Outra mudança importante foi a criação, pela Lei 11.516, de 2007, do Instituto Chico Mendes de Conservação da Biodiversidade, uma divisão do IBAMA com autoridade sobre as unidades de conservação da União.

Quanto ao IBAMA, cabe lembrar que houve um processo de descentralização, especificado na lei 11.284, de 2006, com a transferência de algumas responsabilidades do instituto para estados e municípios. Esse processo, por sua vez, não ficou livre de críticas, pois a maioria dos governos municipais não tem capacidade de implementar as leis florestais (BAUCH et al, 2009). Além disso, a falta de recursos, um dos problemas do órgão, não foi resolvida. Desse modo, apesar das reformas, a ineficiência persiste, e a floresta continua alvo de políticas que, ao invés de a protegerem, estimulam ou, pelo menos, mantêm a insustentabilidade de seu uso. Um exemplo disso é a Medida Provisória (MP) 459, de 2009, a qual, segundo as críticas, abriu caminho para a regularização de ocupações ilegais (BRITO e BARRETO, 2010). Conhecida como "a MP da grilagem", a MP 459 deu origem à Lei 11.952, também de 2009, que manteve as mesmas facilidades. Isso ilustra a frágil e incoerente estrutura institucional da floresta amazônica.

Não podemos esquecer que num passado bem recente o desmatamento na Amazônia esteve intimamente relacionado a políticas de governo para a floresta. O desmatamento era o resultado de uma política oficial que refletia o modelo de desenvolvimento adotado pelo governo federal para o norte do país. Era incentivado, inclusive, com subsídios oferecidos pelos bancos, que também tiveram um papel importante nessa política (TOLLEFSON, 2010). Deve ser lembrado ainda que nos anos 1970 e 1980, a Superintendência para o Desenvolvimento da Amazônia (SUDAM) oferecia recursos financeiros a pecuaristas (FEARNSIDE, 2008). O Banco da Amazônia e o Programa Nacional de Fortalecimento da Agricultura Familiar (PRONAF) também proveram empréstimos que geraram desmatamento. Portanto, o estabelecimento definitivo de uma mudança no modelo de desenvolvimento para região é necessário para que o desmatamento continue em queda.

A situação do tema das florestas no cenário internacional, relegado a um segundo plano, contrasta com a evidência do quanto o desmatamento é um tema proeminente no discurso público. Soma-se a isso o imenso poder sobre o imaginário coletivo, nacional e internacional, que tem o debate em torno da destruição de florestas. Isso torna a ausência do debate sobre florestas, em geral, e sobre a Amazônia, em particular, nas discussões sobre a Rio+20 ainda mais difícil de compreender.

A questão do desmatamento está intimamente relacionada com as áreas protegidas. Esse é o terceiro dos temas sobre a Amazônia que criaram tensão entre a sociedade civil e o governo durante a Rio+20. A MP 558, que reduz o tamanho das unidades de conservação, editada por Dilma Rousseff, foi aprovada pelo Senado no dia 29 de maio de 2012. A medida provisória 558 diminui o tamanho de sete unidades de conservação na Amazônia. A MP se transformou na lei 12.678/2012. No total, 86 mil hectares foram perdidos. A mudança no tamanho das unidades de conservação está diretamente relacionada aos reservatórios de água das hidroelétricas da região (SALOMON, 2012). As hidroelétricas estão se tornando empreendimentos cada vez mais presentes na região. Esse novo cenário é combustível para as críticas de que o modelo de desenvolvimento aplicado na Amazônia ainda é exploratório. A diferença é que agora o que é explorado são seus recursos hídricos, ainda apresentados como energia renovável e, portanto, sustentável, do ponto de vista ambiental. 
O quarto tema relacionado à Amazônia foi o Código Florestal. Antes mesmo de ser votado, o documento já tinha causado repúdio internacional, ficando claro que a presidente Dilma Rousseff tentou evitar que sua votação ocorresse em plena Rio+20. Aproveitando a encruzilhada em que se encontrava a presidente, a oposição se recusou a votar a Lei da Copa sem ter uma previsão para a votação do Código. Isso evidencia como o meio ambiente é visto internamente no circuito de poder brasileiro: uma moeda de troca.

Por todos esses motivos, chegamos a uma conclusão aparentemente paradoxal. Para o governo brasileiro, felizmente, o tema florestas ficou fora da agenda principal da Rio+20. A sociedade civil e as universidades nacionais e internacionais organizaram eventos paralelos que tinham como objetivo debater essas e outras questões relacionadas à Amazônia. Esses quatro temas foram exaustivamente debatidos pela sociedade civil. No entanto, na esfera oficial, as discussões não ocorreram. Os eventos paralelos organizados pelo governo se restringiram à apresentação dos números referentes à queda do desmatamento, deixando as outras questões de lado.

Os quatro temas sobre a Amazônia discutidos fora da reunião oficial estão interligados. A manutenção do baixo nível de desmatamento vai depender da redefinição do modelo de desenvolvimento da região. A construção de hidroelétricas na floresta tropical do norte do país revela que a Amazônia ainda é vista como uma fonte de recursos para o desenvolvimento econômico do Brasil. A diminuição das unidades de conservação para aumentar os reservatórios de hidroelétricas não deixa dúvidas quanto ao papel da floresta nessa fase de crescimento econômico do Brasil.

Os dois principais temas da Rio+20 - economia verde e quadro institucional para o desenvolvimento sustentável - são questões importantes em relação à Amazônia. A transformação da natureza em commodities tem se tornado cada vez mais frequente e aceita. A esperança cega de que o mercado irá resolver os problemas que ele próprio gera chega agora às florestas. Esse é o princípio por trás do pagamento por serviços ecossistêmicos, instrumento que caiu na graça de governos, de empresas privadas e até mesmo de organizações não governamentais. A valoração econômica também é a premissa dos programas de redução de emissões por desmatamento e degradação. O pagamento pelo desmatamento evitado é baseado na economia ambiental. A premissa é a de que o desmatamento ocorre porque os bens públicos que a floresta fornece estão subavaliados no mercado (HUMPHREYS, 2008). Também se fundamenta numa abordagem neoliberal para resolver problemas ambientais. Em vez do governo estabelecer políticas para diminuir o desmatamento, levando em consideração que lugares diferentes apresentam causas distintas para o problema, a solução viria com a redução do papel do Estado e a ampliação do papel do setor privado. Nesse sentido, o perigo de apenas focar no valor comercial da floresta é o de reproduzir os erros do passado, quando a floresta era vista como um lugar vazio e grandes migrações foram incentivadas.

Não podemos esquecer ainda que o fenômeno da globalização também alcançou as florestas. A soja e a carne, commodities no mercado internacional, assim como a madeira, são produtos oriundos da Amazônia. A economia da floresta é responsável por grande parte dos mercados nacionais e internacionais (NEPSTAD, STICKLER e ALMEIDA, 2006). A divisão norte-sul vivenciada nas discussões sobre florestas que antecederam à Rio 92 ainda estão presentes. Com o aumento da importância da conservação de florestas como uma questão política internacional, os países em desenvolvimento tentam incluir no debate temas sobre recursos tecnológicos e financeiros. No entanto, o sucesso não tem sido expressivo.

O quadro institucional para o desenvolvimento sustentável também está intimamente relacionado à floresta amazônica. Mudanças são notórias, mas a estrutura institucional da região ainda deixa a desejar. A falta de preparo, a falta de recursos e a inexistência de uma política clara para a floresta tornam difícil implementar uma gestão sustentável da Amazônia. Apesar de alguns estados brasileiros, como o Acre, serem mundialmente conhecidos por sua iniciativa de "florestania", um misto de floresta com cidadania, no âmbito nacional, a diretriz ainda é pouco definida. O governo federal manda sinais opostos quanto a sua posição política sobre a floresta, e é essa falta de definição clara que impede um resultado mais consistente na busca de outra maneira de ver a Amazônia. 
Entre os múltiplos aspectos da floresta, o potencial econômico ainda é o mais valorizado e domina a agenda política para a região. Por muitas décadas, a Amazônia foi vista como uma questão de segurança e soberania. Os planos de governo e as agências escolhidas para colocar esses planos em prática deixaram isso claro. A visão da Amazônia como uma fronteira econômica permanece imutável. A floresta ainda não foi percebida como uma fronteira ambiental ou estratégica pelo governo brasileiro.

\section{Considerações Finais}

A primeira imagem difundida da Amazônia era a de uma natureza luxuriante, depois a de inferno verde e, finalmente, a de pulmões do mundo e tesouro de biodiversidade. A Amazônia também foi representada como um lugar inabitado, fundando o mito da terra virgem. Apesar de pouco refletirem a realidade da floresta tropical sul-americana, essas múltiplas representações demonstram como a Amazônia se presta a uma infindável produção de percepções, crenças e fantasias a seu respeito. A vasta extensão da floresta no Brasil e o fato de - apesar dos grandes avanços em anos recentes na integração da região ao restante do país muitos brasileiros ainda desconhecerem a região ajudam a manter o ar de mistério em torno da floresta. Essa é a terra de lendas como a do boto rosa, a da cobra grande e Macunaíma. A Amazônia ainda apresenta muitas áreas pouco conhecidas, verdadeiras fronteiras do conhecimento. Esse é o caso da biodiversidade da floresta, pouco explorada e com grandes promessas farmacológicas. Outro pronto importante é a população da Amazônia, rural e urbana, pré-colombiana e contemporânea.

Os avanços em algumas áreas, como no combate ao desmatamento, são inegáveis. No entanto, as principais políticas de desenvolvimento ainda são delineadas de cima para baixo, num movimento caracterizado pela fragmentação institucional e pela presença insidiosa da dicotomia meio ambiente/desenvolvimento (MAY e MILLIKAN, 2010). Apesar das mudanças, a visão da Amazônia como uma fonte inesgotável de recursos ainda prevalece como paradigma que norteia a ação dos tomadores de decisão (HALL, 2008). Não houve ainda um efetivo esforço político para integrar questões ambientais em políticas de desenvolvimento. A falta de uma política nacional clara e coerente no presente mostra como o futuro da Amazônia ainda sofre a influência de insistentes equívocos do passado (BARROS-PLATIAU, 2006).

\section{Referências}

ANTIQUERA, D. A Amazônia e a política externa brasileira: análise do Tratado de Cooperação Amazônica (TCA) e sua transformação em organização internacional (1978-2002). 2006. 203 p. Dissertação (Mestrado em Relações Internacionais) - Instituto de Filosofia e Ciências Humanas da Universidade Estadual de Campinas, 2006.

BARROS-PLATIAU, A. A Política Externa Ambiental: do desenvolvimentismo ao desenvolvimento sustentável. In: ALTERMANI, H.; LESSA, A. C (Orgs.) Relações Internacionais do Brasil - temas e agendas. São Paulo: Saraiva, 2006. v. 2. p. 181-252.

BAUCH, S. et al. Forest policy reform in Brazil. Journal of Forestry, p. 132-138, April/May 2009.

BECKER, B. Amazônia: geopolítica na virada do III milênio. Rio de Janeiro: Garamound Universitária, 2004. 168p.

A Amazônia e a política ambiental brasileira. In: SANTOS, S.; BECKER, B. (Eds.) Território, territórios: ensaios sobre o ordenamento territorial. 3. ed. Rio de Janeiro: Lamparina, 2007. p. 22-42.

.; STENNER, C. Um futuro para a Amazônia. São Paulo: Oficina de Textos, 2008. 150p.

BITENCOURT, R. Nesa espera acertar empréstimo para Belo Monte até meados de dezembro. Valor Econômico, São Paulo, 03 nov. 2011. Disponível em: <http://www.valor.com.br/empresas/1081846/nesa-espera-acertar-emprestimopara-belo-monte-ate-meados-de-dezembro>. Acesso em: 28 jul. 2012.

BOYD, E. Navigating Amazonia under uncertainty: past, present and future environmental governance. The Royal Society Biological Sciences, London, v. 363, p. 1911-1916, 2008. 
BRITO, B.; BARRETO, P. Primeiro ano do programa Terra Legal: avaliação e recomendações. Imazon. 2010. 62p.

Disponível em: <http://www.amazonia.org.br/arquivos/372125.pdf> Acesso em: 10 dez. 2010.

BROWN, K. Cut and run? Evolving institutions for global forest governance. Journal of International Development, v. 13, p. 893-905, 2001.

CENTRO DE GESTÃO E ESTUDOS ESTRATÉGICOS (CGEE). REDD no Brasil: um enfoque amazônico: fundamentos, critérios e estruturas institucionais para um regime nacional de redução de emissões por desmatamento e degradação. Ed. rev. Brasília, DF, 2011. 153p.

CHATTERJEE, R. The road to REDD. Environmental Science and Technology, v. 43, p. 557-560, 2009.

DA SILVA, J.; RYLANDS, A.; DA FONSECA, G. O Destino das áreas de endemismo da Amazônia. Megadiversidade, v. 1, n. 1, p. 124-131, 2005.

DIMITROV, R. Hostage to norms: states, institutions and global Forest politics. Global Environmental Politics, v. 5, n. 4 , p. $1-24,2005$.

EWERS, R.; LAURANCE, W. Scale-dependent patterns of deforestation in the Brazilian Amazon. Environment Conservation, v. 33, p. 203-211, 2006.

FALEIRO, A. O desenvolvimento na Amazônia na visão dos produtores familiares rurais. In: VIANA, G.; SILVA, M.; DINIZ, N. (Orgs.). O desafio da sustentabilidade: um debate socioambiental no Brasil. São Paulo: Editora Fundação Perseu Abramo, 2001. p. 315-329.

FEARNSIDE, P. Amazon forest maintenance as a source of environmental services. Annals of the Brazilian Academy of Sciences, v. 80, n. 1, p. 101-114, 2008.

GARDA, A.; DA SILVA, J.M.; BAIAO, P. Biodiversity conservation and sustainable development in the Amazon. Systematic and Biodiversity, v. 8, n. 2, p. 169-175, 2010.

GUIMARÃES. R. The ecopolitics of development in the Third World: politics and environment in Brazil. Boulder, CO, USA: Lynne Rienner Publishers, 1991. 270p.

HALL, A. Better RED than dead: paying the people for environmental services in Amazonia. Philosophical Transactions of the Royal Society B, London, 2008. p. 1-8.

HOLMGREN, L. International forest policy: an overview. Report from the Secretariat for International Forestry Issues, SIFI, n. 6, 2010. 52p. Disponível em: <http://www.ksla.se/wp-content/uploads/2010/12/KSLAT-6-2010International-forest-policy.pdf>. Acesso em: 28 jul. 2012.

HOORN, C. et al. Amazonia through time: Andean uplift, climate change, landscape evolution and biodiversity. Science, v. 330, p. 927-931, 2010.

HUMPHREYS, D. The politics of 'avoided deforestation': historical context and contemporary issues. International Forestry Review, v. 10, n. 3, p. 403-442, 2008.

HURRELL, A.; KINGSBURY, B. The international politics of the environment: an introduction. In: HURRELL, A.; KINGSBURY, B. (Eds.). The International Politics of the Environment. New York: Oxford University Press, 1992. p. $1-47$

LEWINSOHN, T. O conhecimento e a ignorância sobre a biodiversidade brasileira (Entrevista). Instituto Humanitas Unisinos Online. São Leopoldo, mar. $2006 . \quad$ Disponível em: <http://amaivos.uol.com.br/amaivos09/noticia/noticia.asp?cod_canal=49\&cod_noticia=7066>. Acesso em: 29 jul. 2012.

MANSUR, A. O tabu das hidroelétricas na Amazônia. Época, São Paulo, 10 mar. 2011. Disponível em: <http://revistaepoca.globo.com/Revista/Epoca/0,EMI217431-15223,00-

O+TABU+DAS+HIDRELETRICAS+NA+AMAZONIA.html>. Acesso em: 28 jul. 2012.

MAY, P.; MILLIKAN, B. The context of REDD+ in Brazil: drivers, agents and institutions. Occasional Paper 55. CIFOR, Bogor, Indonesia, 2010. 69p. 
MINISTÉRIO DO MEIO AMBIENTE. Agenda 21. Disponível em: <http://www.mma.gov.br/responsabilidadesocioambiental/agenda-21>. Acesso em: 28 Jul. 2012.

NEPSTAD, C.; STICKLER, C. M.; ALMEIDA, O. Globalisation of the Amazon soy and beef industries: opportunities for conservation. Conservation Biology, v. 20, n. 6, p. 1595-1603, 2006.

OPHULS, W. Ecology and the politics of scarcity. San Francisco: W. H. Freeman and Company, 1977. 303p.

RICHARDS, M.; JENKINS, M. Potential and challenges of payment for ecosystem services from tropical forests. Forest Briefing 16. Overseas Development Institute, Forest Policy and Environment Programme, Dec. 2007. 8p.

ROSENDAL, K. Overlapping International Regimes: the case of intergovernmental forum on forests (IFF) between climate change and biodiversity. International Environmental Agreements: Politics, Law and Economics, v. 1, p. 447-468, 2001.

SALOMON, M. MP tenta conter redução de áreas de proteção na Amazônia 2012. Estadão, São Paulo, 16 jul. 2012. Disponível em: <http://www.estadao.com.br/noticias/vidae,mp-tenta-conter-reducao-de-areas-de-protecao-naamazonia,901075,0.htm>. Acesso em: 28 jul. 2012.

TOLLEFSON, J. The global farm. Nature, v. 466, p. 554-556, July 2010.

UNITED NATIONS. Draft zero. Documento preparatório das Nações Unidas para a Rio+20. Nova York, 10 Jan. 2012a, 19p.

The future we want. Documento final da Convenção das Nações Unidas sobre Desenvolvimento Sustentável. Rio de Janeiro, 20-22 jun. 2012b. 53p.

VIANA, G. Impactos ambientais da política de globalização da Amazônia. In. VIANA, G.; SILVA, M.; DINIZ, N. (Orgs.). O desafio da sustentabilidade: um debate socioambiental no Brasil. São Paulo: Editora Fundação Perseu Abramo, 2001. p. 265-288. 